\title{
Prepona pheridamas pheridamas (Cramer) e seus estágios imaturos (Lepidoptera, Nymphalidae, Charaxinae)
}

\author{
Eurides Furtado ${ }^{1}$
}

\begin{abstract}
Prepona pheridamas pheridamas (Cramer) and its immature stages (Lepidoptera, Nymphalidae, Charaxinae). Data on immature stages and range extension of Prepona pheridamas (Cramer, 1777) are presented. The larva feed on Hirtella gracilipes (Hook. f.) (Chrysobalanaceae), the same natural hostplant for Agrias claudina godmani Fruhstorfer, 1895 in the high Rio Arinos region, Mato Grosso State.

KEY WORDS. Chrysobalanaceae, Hirtella gracilipes, hostplant, immature stages, Prepona pheridamas
\end{abstract}

A distribuição espacial de Prepona pheridamas (Cramer, 1777), com subespécies de valor taxonômico duvidoso, é bastante ampla nas bacias dos rios Orinoco e Amazonas e nas Guianas (D’ABRERA 1987; NEILD 1996); na bacia do rio da Prata, na Serra do Tombador, Nobres, Mato Grosso (TALBot 1928), em Teodoro Sampaio, São Paulo (Mielke \& CASAGRANDE 1997); nas bacias do rio São Francisco em Minas Gerais, e Leste no Espírito Santo (FrUHSTORFER in SEITZ 1907-1924).

Neste trabalho são descritos e ilustrados a cores pela primeira vez os éstágios imaturos desta espécie.

\section{MATERIAL E MÉTODOS}

Ao colher folhas de Hirtella gracilipes (Hook. f.) (Chrysobalanaceae) para alimentar larvas de Agrias claudina godmani Fruhstorfer, 1895 em cativeiro, foi encontrada em suas ramagens uma larva adulta muito semelhante às desta última espécie, que mais tarde originou um belo exemplar de $P$. pheridamas pheridamas. Posteriormente, foram coletadas algumas fềmeas desta espécie e aprisionadas em viveiros de tela plástica envolvendo ramagens vivas de $H$. gracilipes. Alimentadas com frutos fermentados, iniciaram a postura alguns dias depois. As larvas resultantes aceitaram imediatamente a planta e foram mantidas nesta e nos mesmos viveiros, com desenvolvimento e mortalidade normal, até o final do estágio.

Viveiros montados em árvores vivas proporcionam ótimos resultados na criação de insetos. As larvas ficam protegidas de predadores e das conseqüências das intempéries climáticas; têm alimentação farta e fresca o tempo todo e a boa ventilação interior impede ou dificulta a proliferação de doenças viróticas ou fúngicas. Assim, a sobrevivência das larvas em cativeiro pode chegar a mais de $30 \%$, com equilibrio da sexus ratio, quando na natureza apenas pouco mais de $1 \%$ têm a chance de chegar ao final do ciclo e perpetuar a espécie.

A maioria dos adultos obtidos neste estudo foi liberada na natureza, visando não só o equilíbrio, mas também a ampliação populacional desta bela espécie, ameaçada pela destruição impiedosa de nossas florestas.

1) Caixa Postal $97,78400-000$ Diamantino, Mato Grosso, Brasil. 


\section{RESULTADOS}

\section{Ovo (Fig. 1)}

Esférico, cório liso, coloração pérola-clara, $2,3 \mathrm{~mm}$ de diâmetro. Período embrionário, sete dias.

\section{Larva}

Primeiro ínstar (Fig. 2). Cabeça cordiforme, castanho-clara, peças bucais castanho-escuras, ocelos pretos. Tegumento pubescente, área laterodorsal verdeoliva, gradativamente mais claro com séries de pontuação castanho-escura nos últimos segmentos abdominais, estes mais marcados nas áreas dorsal e subdorsal. Tubérculos subdorsais em A2 com a porção apical branca. Faixa espiracular esbranquiçada, pouco visível. Espiráculos elipsoidais, peritrema preto, pouco visíveis, exceto o protorácico. Área ventral verde-clara. Pernas torácicas e abdominais castanho-claro translúcidas. Placa supranal bífida, castanho-clara. Comprimento da larva ao eclodir, 7,0 mm; no final do ínstar, 10,5 mm. Duração, oito dias.

Segundo ínstar (Fig. 3). Cabeça piramidal com dois escolos dorsais fundidos, castanhos com a porção apical mais clara; fronte castanha com minúscula pontuação mais clara, suturas proeminentes; área lateral da mesma coloração frontal, mas com a pontuação mais evidente e esbranquiçada. Tubérculos como no ínstar anterior mas com a área basal castanho-avermelhada. Faixa espiracular mais evidente. Tegumento oliváceo com marmorizações castanho-escuras, com mais nitidez na área dorsal de T3 a A4; áreas ventral e subespiracular com as marmorizações avermelhadas. Pernas castanho-avermelhadas. Comprimento, 15,0 mm. Duração, sete dias.

Terceiro ínstar (Fig. 4). Cabeça como no ínstar anterior, mas com os escolos maiores. Tegumento castanho-avermelhado escuro da faixa espiracular ao dorso; e desta faixa à área ventral, castanho com marmorizações mais claras e pontuação esbranquiçada. Projeções da placa supranal mais longas e coloração mais escura. Demais características como no ínstar anterior. Comprimento, 22,0 mm. Duração, sete dias.

Quarto ínstar (Fig. 5). Cabeça com o mesmo formato e coloração básica do instar anterior; frontoclípeo mais escuro e com cerdas esbranquiçadas até parte do epicrânio; ocelos pretos; área lateral com a coloração mais clara; protuberâncias espinhosas no occipício até parte dos escolos. A pontuação do tegumento neste ínstar é mais forte e as projeções da placa supranal curvadas dorsalmente. Demais características como no ínstar anterior. Comprimento, 33,0 mm. Duração, oito dias.

Quinto ínstar (Figs. 6-7). Cabeça com o mesmo formato anterior; escolos mais escuros; área lateral castanho-rósea com a rugosidade mais escura; occipício com as pequenas protuberâncias espinhosas, pretas. Pronoto mesclado de preto. A2-6 com dois pontos mais claros que o tegumento, um em cada lado da linha dorsal. Tubérculos de $\mathrm{A} 2$ arredondados, com a área basal escura e com pontuação preta brilhante, e em seguida coloração castanho-avermelhada com pontuação esbranqui- 

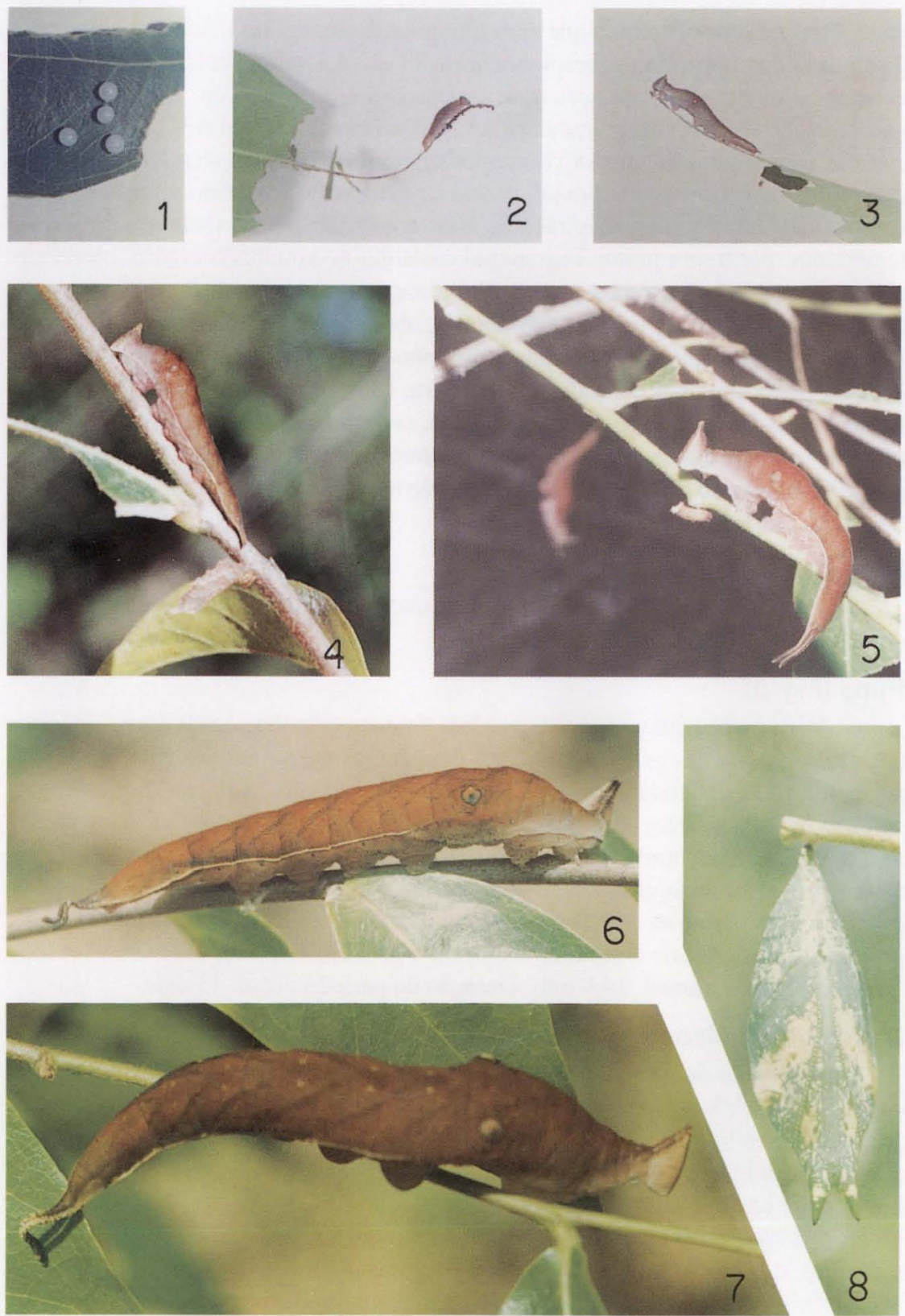

Figs 1-8. Prepona pheridamas pheridamas, formas imaturas. (1) Ovos; (2-7) larva: (2) primeiro instar, vista lateral; (3) segundo instar, vista lateral; (4) terceiro instar, vista lateral; (5) quarto instar, vista laterodorsal; (6-7) quinto instar: (6) vista laterodorsal, (7) vista dorsal; (8) pupa, vista ventral. 
çada, estas maiores à medida que aproximam-se da área dorsal. A faixa espiracular é subdividida: a primeira subespiracular de T1 até A3, com a coloração castanhoescura até $\mathrm{A} 1$ e com a pontuação mais escura daí à sua junção com a segunda faixa, esta castanho-escura, subespiracular em A2, supraespiracular em A3-7, inicialmente estreita, esbranquiçada, em A8 volta a ser subespiracular e mais larga até fundir-se com as projeções da placa supranal. Pernas castanho-claras, as abdominais e as anais com cerdas translúcidas. Espiráculos com coloração pouco mais escura que o tegumento, peritrema preto. Tegumento castanho-avermelhado escuro, mesclado com micro pontuação branca e preta, da área supraespiracular ao dorso. Segmentos abdominais com faixas pretas laterodorsais, obliquas, pouco visíveis em A1, A9 e A10. Área supraespiracular do tórax, castanho-rósea com pontuação preta. Projeções da placa supranal curvadas em corcova, com a porção terminal virada para baixo, formadas com rugosidade espinhosa, coloração castanho-escura com marmorizações mais claras e esbranquiçadas laterodorsais até $2 / 3$ de sua extensão e a partir daí coloração preta até próximo à porção terminal, esta branca. Comprimento, 67,0 mm. Duração, 22 dias.

\section{Pré-pupa}

Tegumento esverdeado-translúcido, marmorizações castanhas bastante evidentes. Duração, dois dias.

\section{Pupa (Fig. 8)}

Vértice com duas projeções agudas. Antenas salientes. Áreas dorsal do tórax e lateral na dobra das asas, acuminadas. Espiráculos elipsóides, irregulares, salientes, coloração mais clara que o tegumento, peritrema preto. A10 rugoso no dorso e sulcado na área ventral. Tegumento áspero, formado com minúscula rugosidade; verde-oliváceo com marmorizações lácteo-ferruginosas, estas mais concentradas na metade distal dos estojos das asas, em pequena porção pouco abaixo dos olhos, nas projeções cefálicas e na área laterodorsal de T1 a A4. Coloração preta no ápice das projeções cefálicas e no cremaster. Comprimento, 39,0 mm. Largura maior, ventral, 15,0 mm; menor, dorsal, 14,0 mm. Duração do período pupal, 13 dias.

\section{Dados bionômicos}

Na região do alto Rio Arinos, Mato Grosso, procedência do material estudado, $P$. pheridamas pheridamas (Figs 9-10) voa durante os meses de janeiro-março, julho-setembro e dezembro. Seus caracteres cromáticos ventrais são inconfundíveis em ambos os sexos e o seu comportamento é o típico do gênero. Voa nas horas mais ensolaradas do dia nas clareiras e bordas das matas. Seus alimentos preferidos são os excrementos preferentemente de animais carnívoros, frutos fermentados, e excreções de certas plantas, oriundas de lesões em seus troncos.

Os ovos são postos isolados na face inferior das folhas da planta hospedeira. Neste estudo o ciclo evolutivo foi de 74 dias. 

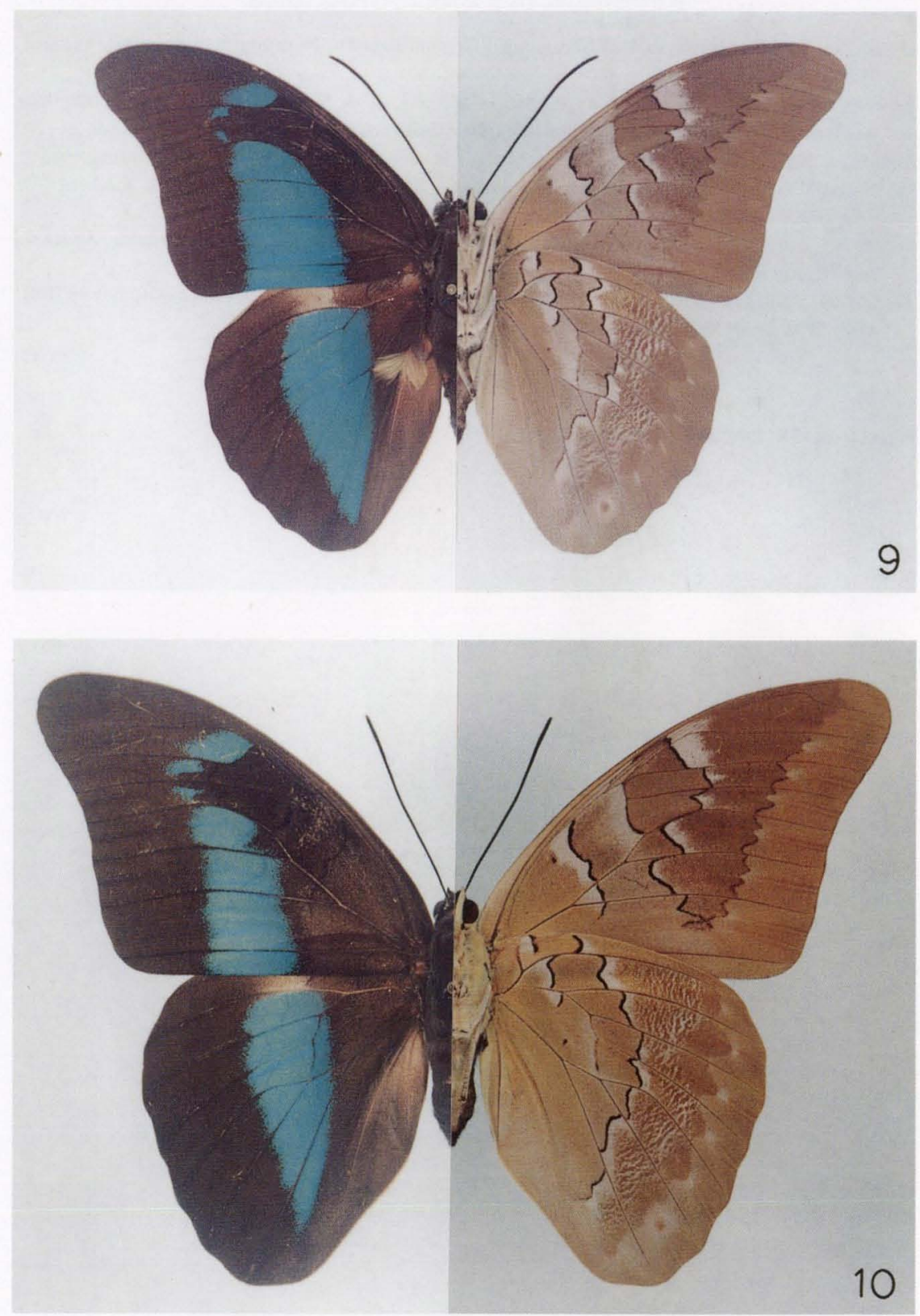

Figs 9-10. Prepona pheridamas pheridamas, adultos. (9) Macho; (10) fêmea. Metade esquerda, vista dorsal e metade direita, vista ventral. 


\section{REFERÊNCIAS BIBLIOGRÁFICAS}

D'ABRera, B. 1987. Butterflies of Neotropical Region, Part IV. Nymphalidae (Partim). Victoria, Hill House, XIII +526-678.

Fruhstorfer, H. 1912-1916. Prepona, Agrias, p. 550-577. In: A. Seitz (Ed.). Die Gross-Schmetterlinge der Erde. Die amerikanischen Tagfalter. Stuttgart, Alfred Kernen, Vol. 5, 1141p.

MielKe, O.H.H. \& M.M. CASAgrande. 1997. Papilionoidea e Hesperioidea (Lepidoptera) do Parque Estadual do Morro do Diabo, Teodoro Sampaio, São Paulo, Brasil. Revta bras. Zool. 14 (4): 967-1001.

NEILD, A.F.E. 1996. The butterflies of Venezuela. Part 1: Nymphalidae I (Limenitidinae, Apaturinae, Charaxinae). London, Meridian Publ., 144p.

TALBot, G. 1928. List of Rhopalocera collected by Mr. C. L. Collenette in Matto Grosso, Brazil. Bull. Hill. Mus. 2 (3): 192-220.

Recebido em 15.XII.2000; aceito em 12.VII.2001. 